Buana Sains Vol 17 No 1: 19 - 24, 2017

\title{
ANALISIS RESIDU PESTISIDA PADA JERUK MANIS DI KECAMATAN DAU, MALANG
}

\author{
Astri Sumiati dan Reza Prakoso Dwi Julianto
}

Fakultas Pertanian Universitas Tribhuwana Tunggadewi, Indonesia

\begin{abstract}
Abstact
Citrus is one type of fruit that is highly favored by the people. Citrus are susceptible to attack pests and diseases that intensive use of pesticides in the field. Recently, consumers are increasingly critical of fruit quality, so the health and safety aspects of the fruit are increasing. For that one of the quality of fruit that must be met by producers and fruit traders is the minimum level of pesticide residues contained within the fruit must be below the tolerance limits set. The aims of this study is to identify and analyze pesticide residues in citrus fruits in the district of Dau, Malang (a case study in the Village Tegalwaru subdistrict Dau, Malang). This research is a survey and observational with cross sectional approach. Data use of pesticides by farmers was measured by a survey conducted for the farmers and merchants. The measurement results residues acephate, carbofuran, carbosulfan, diazinon, dimethomorp, fenobucarb, profenofos, pyrethrin everything is still below the Limit of Detection (LOD) testing in the laboratory PT. Angler Biochem Lab. In profenofos residue tests on samples found to be higher farmer is $0.108 \mathrm{ppm}$ compared with a sample of traders is $0,050 \mathrm{ppm}$. The conclusions of this study are bauh oranges produced by farmers in the sub-district Tegalwaru Dau, Malang get evidence that pesticide residues are still below the prescribed MRL.

Keywords: Citrus, Food Quality, Pesticides, Profenofos

\section{Pendahuluan}

Jeruk merupakan salah satu jenis buah yang sangat digemari oleh masyarakat. Hal ini terlihat dari impor jeruk yang setiap tahun meningkat dari aspek jenis maupun kuantitas. Dari data produksi nasional 2010, didapatkan bahwa pada tahun 2010 Indonesia masih impor jeruk 160 ribu ton dan akan terus meningkat di tahun 2012 menjadi 179 ribu ton. Peningkatan permintaan buah jeruk diikuti oleh perkembangan konsumen jeruk yang semakin meningkat dan semakin kritis terhadap kualitas buah, maka aspek kesehatan dan keamanan terhadap buah semakin meningkat. Untuk itu salah satu kualitas buah yang

harus dapat dipenuhi oleh produsen maupun pedagang buah adalah kadar batas minimun residu pestisida yang terkandung didalam buah harus berada dibawah batas toleransi yang ditetapkan.

Di daerah kabupaten Malang, kecamatan Dau, jenis jeruk manis menempati produksi yang tertinggi di kecamatan Dau dengan lokasi pertanaman berada di desa Selorejo, Tegalweru, dan Petungsewu. Penerapan sistem hama yang belum optimum menjadikan penggunaan pestisida seringkali melebihi dosis anjuran sehingga hal ini akan banyak berpengaruh terhadap keamanan pangan konsumen buah jeruk (Fajar, 2015).
\end{abstract}


Pemakaian pestisida secara terusmenerus akan meninggalkan residu. Beberapa hasil penelitian melaporkan adanya sejumlah residu insektisida imazalil dan thiabendazole pada semangka, heptaklor, endosulfan, dieldrin dan p,p-DDT pada salak. Sedangkan hasil analisis residu pestisida pada buah jeruk didapati kandungan residu karbamat sebesar 0,09 ppm, diatas batas toleransi yang diperbolehkan (Hartini., 2014). Untuk mengantisipasi bahaya pestisida terhadap kesehatan manusia dan lingkungan maka perlu kajian atau analisis sampai seberapa besar residu pestisida yang terdapat didalam buah jeruk dserta jenis pestisida apa yang terdapat didalam residu buah jeruk sehingga dapat dilakukan pencegahan dan pengendalian residu tersebut sehingga tidak membahayakan bagi manusia dan lingkungan.

\section{Metode}

Kegiatan penelitian berupa survey yang dilakukan kepada petani dan pedagang. Dari ketiga desa sentra produksi jeruk, untuk tahap awal akan dilakukan hanya pada 1 desa yaitu desa Tegalwerudengan mewawancarai 3 petani dan 3 pedagang jeruk. Untuk masing-masing petani akan dibeli jeruk sebanyak $5 \mathrm{~kg}$ demikian pula untuk setiap pedagang juga akan dibeli sebanyak $5 \mathrm{~kg}$ (sekitar 30 buah jeruk manis). Pada penelitian lebih lanjut akan dilakukan pada 4 desa dengan masingmasing 5 petani/desa untuk mengetahui pelaksanaan pengendalian hama.

Buah jeruk yang didapatkan dari setiap petani dan pedagang akan diambil
$3 \mathrm{~kg}$ untuk selanjutnya diukur kadar residu pestisidanya di Laboratorium PT. Angler Biochemlab Surabaya. Kadar residu pestisida diukur dengan metode Gas Chromatografi untuk 2 sample residu buah jeruk yang didapatkan dari ex petani dan ex pedagang.

Data penggunaan pestisida oleh petani jeruk disajikan secara deskriptif dimana dilakukan pengamatan pada kadar residu pestisida dalam buah jeruk untuk kemudian dibandingkan dengan baku mutu SNI 7313: 2008 mengenai Ambang Batas Maksimum Residu pada hasil pertanian.

\section{Hasil dan Pembahasan}

\section{Penggunaan Pestisida Petani Jeruk}

Buah jeruk termasuk dalam kelompok Pangan Segar Asal Tumbuhan (PSAT) yang di atur oleh pemerintah (Permentan no 88 Tahun 2011). PSAT merupakan jenis pangan yang berasal dari tumbuhan berupa berbagai macam produk yang dihasilkan dari proses pasca panen untuk dijadikan bahan pangan atau bahan baku industri, dan atau produk yang mengalami proses secara minimal (produk minimal processing).

Komoditi buah jeruk agar aman dan layak untuk dikonsumsi perlu pengawasan dan melakukan sertifikasi untuk menjamin keamanan konsumen. Petani jeruk di Desa Tegalwaru Kecamatan Dau, Malang menggunakan jenis pestisida sistemik yang tidak sesuai dengan petunjuk yang tertera pada kemasan. 
A. Sumiati dan R. P. D. Julianto / Buana Sains Vol 17 No 1 : 19 - 24

Tabel 1.Dosis dan Frekuensi Pestisida yang Digunakan.

\begin{tabular}{clll}
\hline Jeruk & \multicolumn{1}{c}{ Dosis } & \multicolumn{1}{c}{ Frekuensi } & Kategori \\
\hline A & $\begin{array}{l}\text { 4-7 jenis pestisida, } \\
\text { Tidak sesuai } \\
\text { takaran }\end{array}$ & $\begin{array}{l}\text { Setiap 2 hari sekali selama } \\
\text { masa tanam }\end{array}$ & Tinggi \\
4-6 jenis pestisida, & $\begin{array}{l}\text { Setiap 2-3 hari sekali } \\
\text { selama masa tanam }\end{array}$ & Sedang \\
Tidak sesuai & takaran & & \\
4-6 jenis pestisida, & Setiap 2 hari sekali, mulai & Rendah \\
Tidak sesuai & minggu ke-3 jeruk sudah & \\
takaran & tidak disemprot pestisidal & \\
&
\end{tabular}

Sumber: data primer

Tabel 2. Jenis Pestisida yang digunakan Selama Masa Tanam Jeruk

\begin{tabular}{|c|c|c|c|}
\hline No & Nama & Bahan Aktif & OPT sasaran \\
\hline 1 & Orthen 75 SP & Acephate & $\begin{array}{l}\text { Kutu pucuk wereng (Aphist } \\
\text { tavaresii) }\end{array}$ \\
\hline 2 & Furadan $3 G$ & Carbofuran & Penggerek batang \\
\hline 3 & Dekasulfan 350EC & Carbosulfan & $\begin{array}{l}\text { Kutu Loncat } \\
\text { (Diaphorina citri) }\end{array}$ \\
\hline 4 & Roxion $40 \mathrm{EC}$ & Dimethoate & $\begin{array}{l}\text { Kutu Loncat } \\
\text { (Diaphorina citri) }\end{array}$ \\
\hline 5 & Belvo $80 \mathrm{WG}$ & Acephate & Jamur upas (Oidium tingitanium) \\
\hline 6 & Basudin $60 \mathrm{EC}$ & Diazinon & Kutu Daun (Aphis gossypii) \\
\hline 7 & Acrobat $50 \mathrm{WP}$ & Dimetomorp & Penyakit antaknosa \\
\hline 8 & Ambas $500 \mathrm{EC}$ & Fenobucarb & Ulat Grayak (Spodoptera litura) \\
\hline 9 & Curacron 500EC & Profenofos & $\begin{array}{l}\text { Kutu daun, Thrips, Apis, dan } \\
\text { lalat daun }\end{array}$ \\
\hline 10 & Buldox $25 \mathrm{EC}$ & Pyrethrin & Aphis sp, ulat peliang daun \\
\hline
\end{tabular}

Sumber: data primer

Berdasarkan Tabel 1, diketahui jeruk A dalam kategori "tinggi" dikarenakan petani seringkali pada1 kali masa tanam memakai 7 jenis pestisida dengan frekuensi menyemprot 2 hari sekali, sedangkan jeruk B masuk dalam kategori "sedang" karena petani menggunakan 6 jenis pestisida dengan frekuensi 2-3 hari sekali. Jeruk C masuk dalam kategori "rendah" karena mulai minggu ke-3 petani tidak menyemprot tanamannya dengan pestisida, hal ini disebabkan tanaman jeruk terkena serangan "trips", sehingga petani biasanya merasa pengendalian dirasa sudah gagal sehingga tidak meneruskan penyemprotan sampai panen.

Petani biasanya memakai jenis-jenis pestisida yang meliputi insektisida sistemik dan racun kontak serta fungisida yang bersifat protektif, kuratif dan eradikatif, yaitu:

Jenis merek dagang insektisida sistemik yang digunakan oleh petani 
A. Sumiati dan R. P. D. Julianto / Buana Sains Vol 17 No 1 : 19 - 24

antara lain "Gauco" merupakan insektisida sistemik dengan bahan aktif Imidaklorpid $350 \mathrm{~g} / \mathrm{l}$. Petani Jeruk di Desa Curut biasa menggunakan insektisida "Gauco" ini kurang lebih mulai hari ke 14 sampai hari ke 50, dengan frekuensi setiap 2 hari sekali sangat memungkinkan menyebabkan bahan aktif Imidaklorpid meresap ke dalam bagian-bagian tanaman Jeruk.

"Basudin" dan "Ambas" adalah jenis insektisida racun kontak dan lambung. Racun Kontak akan bekerja dengan baik jika terkena atau kontak langsung dengan hama sasaran. Racun lambung yang terdapat dalam insektisida "Basudin" dan "Ambas" ini baru bekerja jika bagian tanaman yang telah disemprot dimakan oleh hama. Bagian tanaman yang termakan itulah yang akan sampai di lambung hama. Di lambung inilah kerja racun mulai bereaksi.

Fungisida merupakan senyawa kimia yang mempunyai peranan dalam mengendalikan penyakit tanaman yang disebabkan oleh cendawan (jamur). Sifat fungisida ini adalah pengendalian preventif, artinya fungisida ini akan disemprotkan sebagai langkah pencegahan supaya jamur tidak mengganggu tanaman.

Jenis merek dagang fungisida yang digunakan oleh petani sangat beragam antara lain, Belvo, Nativo, dan Heksa. Banyaknya jenis fungisida yang digunakan disebabkan tanaman Jeruk sangat rentan terhadap jamur, sehingga petani akan berusaha dengan maksimal melindungi tanaman Jeruknya dengan menguyur tanaman tersebut dengan larutan fungisida berbagai merek dagang, meskipun dalam label tidak tertulis penggunaanya pada tanaman jeruk.

\section{Kadar Residu Pestisida dalam Buah Jeruk.}

Pola aplikasi petani yang menggunakan beragam jenis pestisida dengan frekuensi penyemprotan yang sering akan meninggalkan residu pada buah jeruk yang dihasilkan, antara lain:

Residu pestisida ditemukan di dalam buah jeruk yang dihasilkan oleh petani, hal ini berkaitan dengan jenis pestisida yang digunakan yaitu insektisida dan fungisida sistemik. Cara kerja dari insektisida sistemik yaitu diserap oleh bagian-bagian tanaman melalui stomata, meristem akar, lentisel batang dan celahcelah alami. Selanjutnya insektisida akan melewati sel-sel menuju ke jaringan pengangkut baik xylem maupun floem. Insektisida akan meninggalkan residunya pada sel-sel yang telah dilewatinya. Insektisida yang disemprotkan akan terbawa melalui pembuluh angkut yang kemudian ditranslokasikan pada bagian bagian tanaman baik yang mengarah keatas (akropetal) maupun kearah bawah (basipetal), juga pada tunah yang baru tumbuh. Sistem kerja dariinsektisida ini adalah mematikan serangga yang memakan bagian tanaman yang terkandung residu insektida

Organophosphat adalah insektisida yang paling toksik diantara jenis pestisida lainnya dan sering menyebabkan keracunan pada manusia. Bila termakan, meskipun dalam jumlah sedikit saja, dapat menyebabkan kematian. Sebagian besar bahan aktif golongan organofosfat sudah dilarang beredar di Indonesia, misalnya diazinon, fention, fenitroteion, fentoat, klorpirifos, kuinalfos, dan malation, sedangkan bahan aktif lainnya masih diijinkan. 
A. Sumiati dan R. P. D. Julianto / Buana Sains Vol 17 No $1: 19$ - 24

Tabel 3. Residu Pestisida Organophosphat dan Karbamat dalam Buah Jeruk

$\begin{array}{cccc}\text { Residu Pestisida } & \text { Sampel Petani } & \text { Sampel Pedagang } & \text { LOD } \\ & \text { Ppm (mg/kg) } & \text { Ppm (mg/kg) } & \text { Ppm (mg/kg) }\end{array}$

\begin{tabular}{lccc}
\hline Acephate & $<0,005$ & $<0,005$ & 5 \\
Carbofuran & $<0,005$ & $<0,005$ & 0,1 \\
Carbosulfan & $<0,005$ & $<0,005$ & 2 \\
Diazinon & $<0,005$ & $<0,005$ & 0,7 \\
Dimethomorp & $<0,005$ & $<0,005$ & 2 \\
Fenobucarb & $<0,005$ & $<0,005$ & 0,5 \\
Profenofos & 0,108 & 0,050 & 1 \\
Pyrethrin & $<0,005$ & $<0,005$ & 0,05 \\
\hline
\end{tabular}

Sumber: data primer

Dari hasil pengujian di laboratorium diketahui untuk kadar residu pestisida kelompok organophosphat (diazinon, parathion, ethion, profenofos, malathion dan chlorpyrifos), semuan jenis residu pestisida masih di bawah Limit Of Detection (LOD), artinya kadar residu pestisida yang diukur tidak terbaca oleh alat. Hal ini mengandung dua kemungkinan, yaitu pada buah Jeruk tidak ditemukan residu pestisida kelompok organophosphat atau kemungkinan ada residu tetapi di bawah nilai LOD dari alat penguiian. Hasil ini kemungkinan juga disebabkan oleh penggunaan formulasi pestida oleh petani jeruk yang mencampur beberapa jenis pestisida sehingga mengakibatkan tidak terdeteksinya residu pestisida pada alat kromatografi gas karena alat tersebut tidak mampu mendeteksi beberapa formulasi pesisida yang dicampur

Penurunan kadar residu pestisida pada pangan dapat dilakukan dengan beberapa pendekatan yaitu secara fisik dan kimia. Kandungan residu pestisida pada produk pertanian dapat dikurangi dengan cara mencuci produk tersebut dengan air yang mengalir untuk beberapa kali, kemudian direndam di dalam air selama satu jam. Beberapa hasil penelitian melaporkan bahwa detergen dapat digunakan untuk melepaskan residu pestisida pada buah-buahan (Indraningsih, 2008). Tetapi untuk buah jeruk hal ini perlu dibuktikan terlebih dahulu karena buah jeruk mempunyai kulit dan biasa dikunsumsi dengan cara segar.

Salah satu cara yang dapat dilakukan untuk menurunkan residu pestisida adalah dengan mengatur jarak/frekuensi penyemprotan pestisida sesuai dengan golongannya karena masa degradasi organophosphat dan karbamat dalam lingkungan sekitar 2 minggu, maka frekuensi/jarak penyemprotan golongan ini adalah 2 minggu sekali.

\section{Kesimpulan}

Simpulan hasil penelitian pada petani jeruk di Desa Tegalweru Kecamatan Dau Kabupaten Malang adalah: 1) Petani menggunakan $4-7$ jenis pestisida insektisida dan fungisida sistemik dalam satu kali masa tanam yang dicampur dalam sekali pemakaian, dengan berbagai macam merek dagang, 2) Petani dalam menggunakan pestisida tidak sesuai dengan petunjuk yang tertera pada kemasan, 3) Buah Jeruk hasil panen petani mengandung residu profenofos (Organophospat) dengan kadar 0,050$0,108 \mathrm{ppm}$. 


\section{Daftar Pustaka}

Anonim, 2004. Metode Pengujian Residu Pestisida Hasil Pertanian. Departemen Pertanian Komisi Pestisida.

Dalimunthe KT, Hasan W, Ashar T. 2012. Analisa Kuantitatif Residu Insektisida Profenofos pada Cabai Merah Segar dan Cabai Merah Giling di Beberapa Pasar Tradisional Kota Medan. Lingkungan dan Kesehatan Kerja. 1 (1): 1- 5.

Fajar. 2015. Melihat Potensi Bukit Jeruk di Malang. Balitjestro. 1 (1):1-3

Hardiyanto, C. Martasari, dan D. Agisimanto., 2004. Rekoleksi, Karakterisasi, dan Konservasi Plasmanutfah Jeruk. (In press). Laporan Akhir Tahun 2004. LokaPenelitian Tanaman Jeruk dan Hortikultura Subtropik.14 hlm

Hartini, Eko. 2014. Kontaminasi residu pestisida dalam buah jeruk (studi kasus pada petani di kecamatan penawangan). Jurnal Kesehatan Masyarakat 10(1) (2014) $96-102$

Karsinah, Sudarsono, L. Setyobudi, dan H. Aswidinnoor. 2002. Keragaman Genetik Plasma nutfah Jeruk Berdasarkan Analisis Penanda RAPD. Jurnal Biotek Pertanian.7(1):8-16

Katharina Oginawati, 2003. Toksikologi Pestisida (dalam Toksikologi Lingkungan, Editor Juli Soemirat). Gajah Mada University Press, Yogyakarta.
Moreno. 2008. Multiresidue Method for the Analysis of More tahn 140 Pesticide residue in Fruits and Vegetables by Gas Chromatography Couples to triple Quadrupole Mass Spectrometry. Journal of Mass Spectrometry, 43: 1235-1254.

Munarso SJ, Miskiyah, Broto W. 2006. Studi Kandungan Residu Pestisida pada Kubis, Tomat dan Wortel Di Malang dan Cianjur. Buletin Teknologi Pascapanen Pertanian. $5: 27-32$.

Mutiatikum, Sukmayati. 2009. Pemeriksaan Residu Pestisida dalam Komodisi Beras yang Berasal dari Beberapa Kota dalam Upaya Penetapan Batas Maksimum Residu (BMR) Pestisida. Media Litbang Kesehatan Volume XIX No. 2 : 54-60.

Sakung, J. 2004. Kadar Residu Pestisida Golongan Organofosfat pada Beberapa Jenis Sayuran. Jurnallmiah Santina 1: 520525.

Sudarmo, S. 2005. Pestisida Nabati.Kanisius. Yogyakarta.

Steenis. C.G.G. J. van. 1992. Flora Untuke Sekolah Di Indonesia. Edisi 6. Jakarta

Tuhumury GNC, Leatemia JA, Rumthe RY, Hasinu JV. 2012. Residu Pestisida Produk Sayuran Segar di Kota Ambon. Agrologi. (1) $2: 99-105$. 